\title{
The Effect of Silver Nanofibers on the Deformation Properties of Blood Vessels: Towards the Development of New Nanotechnologies to Prevent Rupture of Aneurysms
}

\author{
Miguel Gonzalez, ${ }^{1}$ Daniel Rivera, ${ }^{1}$ Alam Marcelino, ${ }^{1}$ \\ Gabriela Agront, ${ }^{1}$ Rafael Rodriguez, ${ }^{2}$ and Miguel Castro ${ }^{1}$ \\ ${ }^{1}$ Department of Chemistry, Chemical Imaging Center, The University of Puerto Rico at Mayaguez, Mayaguez, PR 00682, USA \\ ${ }^{2}$ University of Puerto Rico, Medical Sciences Campus, San Juan, PR 00936, USA
}

Correspondence should be addressed to Miguel Castro; miguel.castro2@upr.edu

Received 30 October 2013; Revised 10 January 2014; Accepted 9 February 2014; Published 15 May 2014

Academic Editor: Jingxia Wang

Copyright ( $) 2014$ Miguel Gonzalez et al. This is an open access article distributed under the Creative Commons Attribution License, which permits unrestricted use, distribution, and reproduction in any medium, provided the original work is properly cited.

\begin{abstract}
An aneurysm is the result of a widening or ballooning of a portion of a blood vessel. The rupture of an aneurysm occurs when the mechanical stress acting on the inner wall exceeds the failure strength of the blood vessel. We propose an innovative approach to prevent the rupture of an aneurysm based on the use of nanotechnology to improve the strength of the blood vessel. We present results on the effect of silver nanofibers on the resistance toward deformation of blood vessels. The silver nanofibers are grown on the surface of the blood vessels. The nanofibers are $120 \pm 30 \mathrm{~nm}$ in diameter and $2.7 \pm 0.8 \mu \mathrm{m}$ in length. The deformation per applied force of blood vessels was found to decrease from $0.15 \mathrm{~m} / \mathrm{N}$ in control blood vessels to $0.003 \mathrm{~m} / \mathrm{N}$ in blood vessels treated with the nanofibers. This represents an increase in the resistance towards deformation of a factor of 50 . The increase in the resistance towards deformation is clinically significant since blood pressure increases by factors slightly larger than one in the human body. Treatment of blood vessels with silver nanofibers is a potential translational clinical tool for preventing rupture of aneurysms in a clinical setting.
\end{abstract}

\section{Background}

An aneurysm is a condition identified as an abnormal widening or ballooning formation on segments of blood vessels that can result in adverse health effects in the population [1-5]. A few of direct implications of different types of the disease in humans are highlighted in Table 1. The development of an aneurysm in a blood vessel is summarized on Figure 1. The biomechanical properties of blood vessels are disrupted by the shear stress associated with the hemodynamics in the region of an aneurysm. Loss of the blood vessel characteristic elasticity allows a persistent widening of the area and the formation and growth of the aneurysm $[4,5]$. The biomechanical stress exerted by the regional hemodynamic condition allows for a weakening of vessel walls and increases the risk of aneurysm rupture $[4,5]$. Open or endovascular surgery is the recommended treatment for aneurysms that reach a critical size to prevent rupture [2-5]. Open surgery is performed to replace the affected vessel area with a man-made graft [36]. Endovascular surgery, on the other hand, is performed with the insertion of a catheter through the vascular system to reach the affected area. A variety of apparatus or materials, including stents, coils, and polymers, can be inserted through the catheter and placed on the aneurysm area to protect the affected region of the vessel wall from hemodynamic effects $[1,3-5,7-10]$. In the context of the discussion presented above, devices employed to prevent aneurysm rupture are expected to become smaller to reduce the risks associated with invasive endovascular procedures and improve biocompatibility [11-17].

Developments of new imaging tools with increased spatial resolution and the general interest in the biomedical applications of nanotechnology motivate the present study [18-27]. In particular, the use of nanotechnologies to increase 
TABLE 1: Incidence and risk factors of aneurysms.

\begin{tabular}{ll}
\hline Aneurysm type & Incidence and risk factors \\
\hline Intracranial aneurysm (IC) [7] & $\begin{array}{l}\text { About 30,000 patients are treated for IC ruptures each year in the US 60\% of these } \\
\text { cases ended up with disabilities or dead }\end{array}$ \\
\hline Thoracic aortic aneurysm (TAA) $[32,33]$ & $\begin{array}{l}\text { Incidence of } 10.4 \text { per } 100,000 \text { persons per year } 2.9 \text { to } 3.5 \text { rupture cases per } 100,000 \\
\text { people annually }\end{array}$ \\
\hline $\begin{array}{l}\text { Abdominal aortic aneurysm (AAA) } \\
{[4,32,34,35]}\end{array}$ & $\begin{array}{l}150,000 \text { cases per year } \\
\text { Distribution of } 12.5 \% \text { in men and } 5.2 \% \text { in women in people between } 75 \text { and } 84 \text { years } \\
\text { of age } \\
\text { Ruptures have a } 90 \% \text { risk of death }\end{array}$ \\
\hline
\end{tabular}

the strength of blood vessels in the early stages of formation of aneurysms may prevent growth of the widening area. In this regard, molecularly guided assembly offers the opportunity to grow nanofibers directly on the tissue and it represents a unique opportunity for developing technologies acting on tissue-specific locations $[28,29]$. Here, we report on the use of molecularly guided assembly of nanoparticles into a mesh consisting of nanofibers for improving the strength of blood vessels. We have explored the growth of silver nanofibers on the surface of blood vessels endothelial surfaces obtained from sus scrofa domestica (domestic pig) with the purpose of contributing to the current body of knowledge related to the applications of nanotechnology in biomedical science and tissue bioengineering research. The nanofibers are composed of small particles and clusters. This innovative approach targets novel biomedical applications for preventing the rupture of aneurysms. It is based on the assembly of silver into one dimensional nanostructures guided by mercaptoacetic acid $\left(\mathrm{HSCH}_{2} \mathrm{CO}_{2} \mathrm{H}\right)[30,31]$. The sulfur end of the thiol molecule attaches to silver, while the carboxylic acid end forms hydrogen bonds to the carboxylic acid end of another thiol which in turn is bonded to silver. The nanofibers form when water is removed from the dispersion and is completely irreversible. We found that the silver nanofibers increase the resistance of blood vessels towards deformation as compared to untreated tissue.

\section{Materials and Methods}

2.1. Synthesis of Silver-Thiol Dispersion: Precursors to Silver Nanofibers. About two (2) micrograms ( $\mu \mathrm{g})$ of silver nitrate $\left(\mathrm{AgNO}_{3}\right.$, Fisher $)$ were mixed with an equivalent number of moles of mercaptoacetic acid $\left(\mathrm{HSCH}_{2} \mathrm{CO}_{2} \mathrm{H}\right.$, Aldrich) and $10.0 \mathrm{~mL}$ of deionized water. The mixture was shaken by hand for a few of seconds and the suspension was stored at dark under room temperature.

2.2. Blood Vessels. Blood vessels were obtained from the head of a sus scrofa domestica that was donated by a local slaughter house: the animal was killed for marketing purposes and not for the measurements reported here. The head was kept frozen in a refrigerator and was allowed to defrost prior to the removal of samples containing blood vessels. Blood vesselcontaining tissue samples were cut in sections measuring

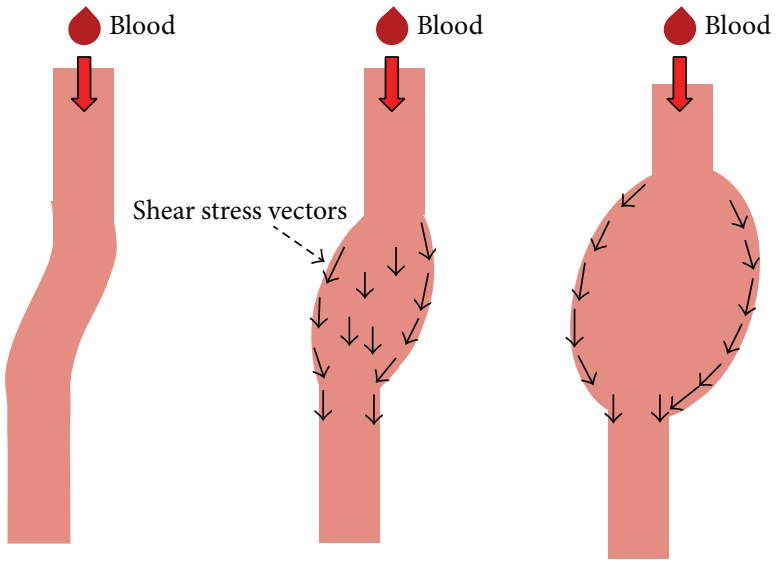

FIgURE 1: The formation and growth of aneurysm due to the shear stress caused by the intermittent blood flow. The drawing is intended to guide the eye through the text.

approximately $10 \mathrm{~cm}$ in length. A flow of air was passed through selected blood vessels to facilitate the dissection from the tissue (Figure 2(a)). Sections of the blood vessels were cut wide open to expose the internal endothelial surface. The blood vessel sections employed for the measurements presented in this work were $2 \mathrm{~cm}$ long, $2 \mathrm{~cm}$ wide and between 1 and $4 \mathrm{~mm}$ in depth (Figure 2(b)).

2.3. Preparation of Blood Vessels Treated with Nanofibers and Control Tissue. Regions of the internal endothelial surface of the blood vessels were treated with a total volume of $60.0 \mu \mathrm{L}$ of the silver-thiol dispersion in $10 \mu \mathrm{L}$ incremental steps. The internal blood vessels' endothelial surfaces were allowed to dry in air to allow for the formation of the silver nanofibers. Control tissue was prepared by treating regions of the internal endothelial surface of the blood vessels with a total volume of $60.0 \mu \mathrm{L}$ of $\mathrm{H}_{2} \mathrm{O}$ in $10 \mu \mathrm{L}$ incremental steps.

\subsection{Characterization of Nanofibers}

2.4.1. SEM Imaging. SEM images were obtained with an environmental JEOL JSM-6460 LV SEM. Blood vessels were fixed to a conductive carbon tape and placed in the SEM analysis chamber. SEM images were collected with an acceleration 


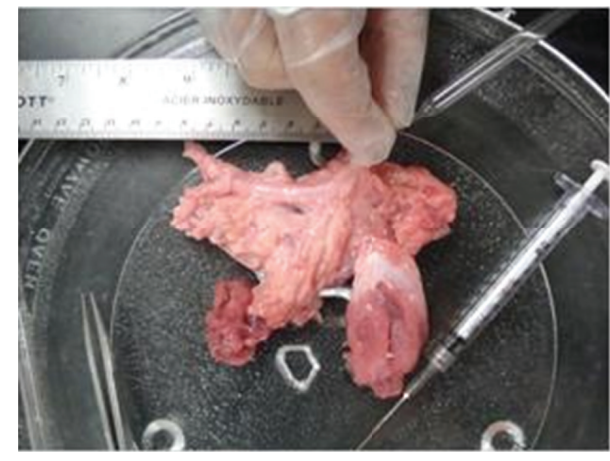

(a)

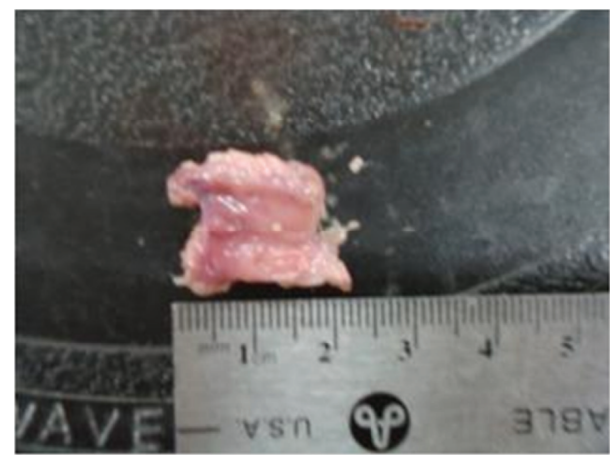

(b)

FIGURE 2: (a) Representative images of pieces of tissue containing blood vessels and (b) a piece of blood vessel cut wide open.

voltage of $5 \mathrm{kV}$ in the high vacuum mode with spot sizes between 35 and 40 . The diameter and length of the nanofibers were estimated from the SEM images using the software package provided by JEOL.

2.4.2. UV-Visible Measurements. UV-visible absorption spectroscopy measurements on dry deposits of the nanofibers formed on the surface of the blood vessels were performed with an Ocean Optics 2000 spectrometer coupled to an Olympus microscope operated in the reflection mode and UV grade optics. The Mie model of spheres and wires was used for simulation of the optical absorption spectrum [36]. The simulations were performed in a Dell PC using Igor software.

\subsection{Determination of Displacement as a Function of Pressure.} The deformation of the tissue was determined by applying a force with a pin. The blood vessel samples were placed on a flat aluminum holder. The holder has an aperture that is $1 \mathrm{~cm}$ in diameter to allow the pin to come in contact with the blood vessel surfaces. The area of the pin that comes into contact with the sample is $1.5 \mathrm{~mm}^{2}$. A cantilever system was developed and employed to apply the force on the tissue (see Figure 3). The cantilever consisted of a pin $(d=1.4 \mathrm{~mm})$ glued to the inner wall of a glass cylinder and a recipient at the other end to place a weight. The force was controlled by placing a known weight of sand on the recipient to drive the movement of the tip upward at the other end. The mass of the sand was determined with a Mettler Toledo microbalance model AT 20. The microbalance allowed the determination of the mass of the sand to within $10^{-6}$ grams. The displacement was determined using a calibrated ruler placed next to the tip. The displacement was recorded with a standard digital camera and was determined using commercially available software. A few micrograms of sand are needed to get the pin in touch with the tissue (region A). There is a region in which further addition of mass does not result in a measureable displacement (region B) until a small amount of sand added to the counterweight results in a displacement of the tip (Region C). That point is taken to correspond to the minimum force required to bend the internal blood vessels' endothelial surface.

\section{Results}

3.1. Optical Absorption Spectroscopy Measurements. The absorption spectra of thiol-silver dispersions have been published elsewhere [30]. It has absorption peaks due to silver dimers $\left(\mathrm{Ag}_{2}\right)$ in the ultraviolet region at $260 \mathrm{~nm}$ and $280 \mathrm{~nm}$ as well as a broader band resulting from light absorption by silver nanoparticles at $360 \mathrm{~nm}$. Representative UV-visible absorption spectrum of the nanofibers grown on the blood vessel surface is illustrated on Figure 4. The experimental spectrum of the nanofibers that are formed when the water is removed from the dispersion has a continuous absorption band from the UV to the visible. No evidence is found for a localized band in the absorption spectrum of the nanofibers, in marked contrast to the absorption spectrum of the dispersion used to prepare the nanofibers that exhibits well-defined bands due to the absorption of light by silver nanoclusters and nanoparticles [30].

Light absorption by metallic silver results from a collective excitation of electrons known as plasmons. Silver nanoparticles have a transverse plasmon mode while a longitudinal plasmon mode can be observed in the spectrum of silver nanowires. Simulations of the absorption spectrum of wires and particles provided insight about the electronic excitations that contribute to the absorption spectrum of the nanofibers. The inserts (b) and (c) in Figure 4 illustrate computer simulations using Mie theory of the light absorption of particles and wires, respectively [36]. The simulation assumes wires with a length and diameter of $1 \mu \mathrm{m}$ and $50 \mathrm{~nm}$, respectively. The diameter of the spheres used in the simulation is $30 \mathrm{~nm}$. The light absorbed by the wires is predicted to decrease with wavelength between 200 and $300 \mathrm{~nm}$ and to exhibit a sharp increase at $310 \mathrm{~nm}$ until it peaks at $360 \mathrm{~nm}$. The amount of light absorbed by the wires is predicted to decrease gradually with wavelength from $360 \mathrm{~nm}$ up to $1000 \mathrm{~nm}$. The spectrum simulated for the spheres, on the other hand, has a well-defined absorption band centered on $380 \mathrm{~nm}$. The absorption spectrum of the nanofibers is remarkably similar to the one simulated for the wires. Thus, the tail toward long absorption wavelengths observed in the spectrum of the nanofibers results from excitations of the longitudinal plasmon mode in silver. This interpretation highlights the metallic character of the nanofibers that result 

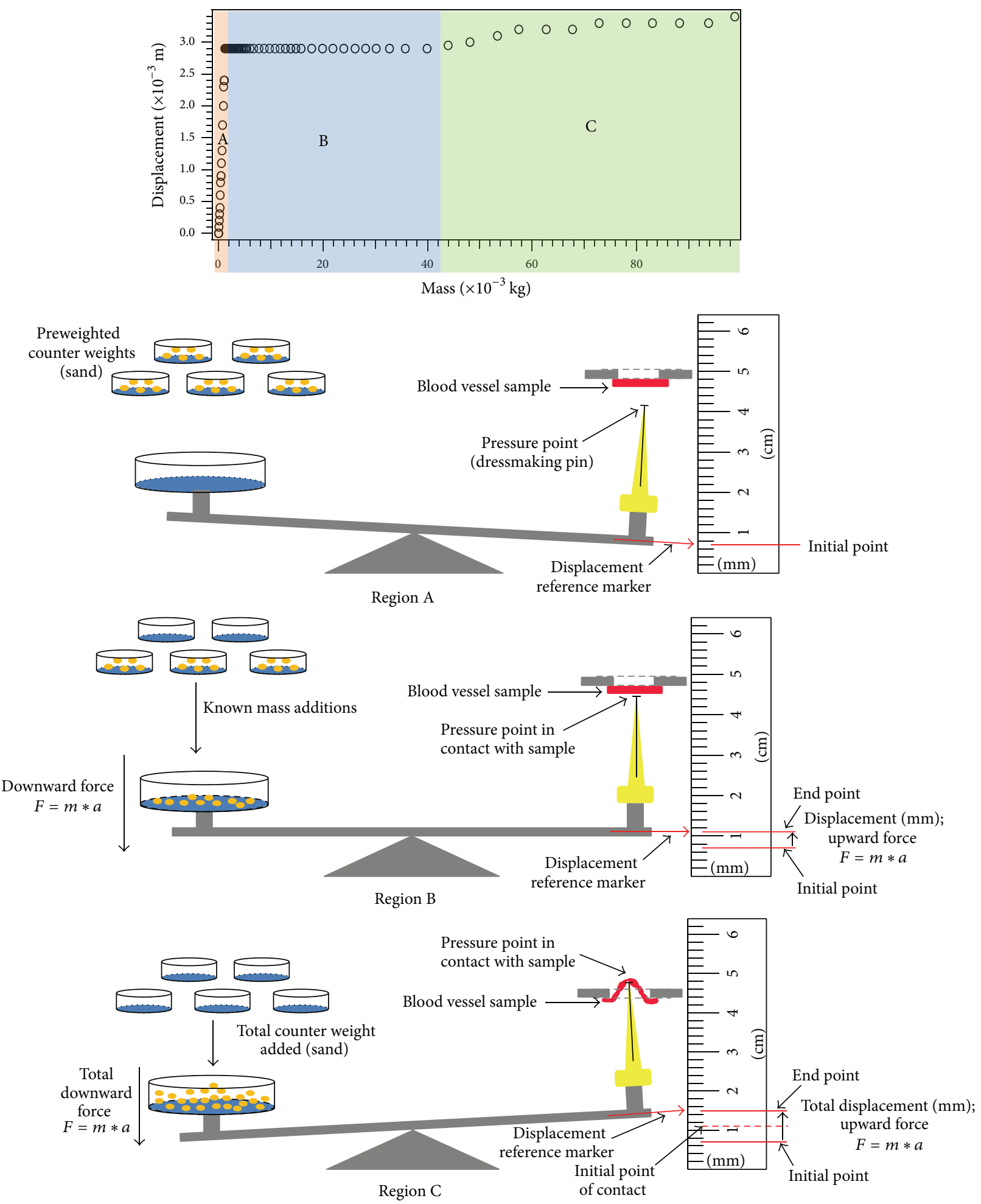

FIGURE 3: Experimental set up used to measure tissue deformation as a function of applied pressure. The pin has a free displacement (region A) until it reaches contact with the tissue (region B). There is a range in which the pressure applied with the pin is not enough to cause a deformation in the tissue, highlighted as region B in the figure. Further increase in the force applied with the pin results in the deformation of the tissue which is measured by a change in the displacement of the pin as highlighted by region $\mathrm{C}$ in the same figure. The force applied is estimated by the mass of the sand used to drive the movement of the pin. 


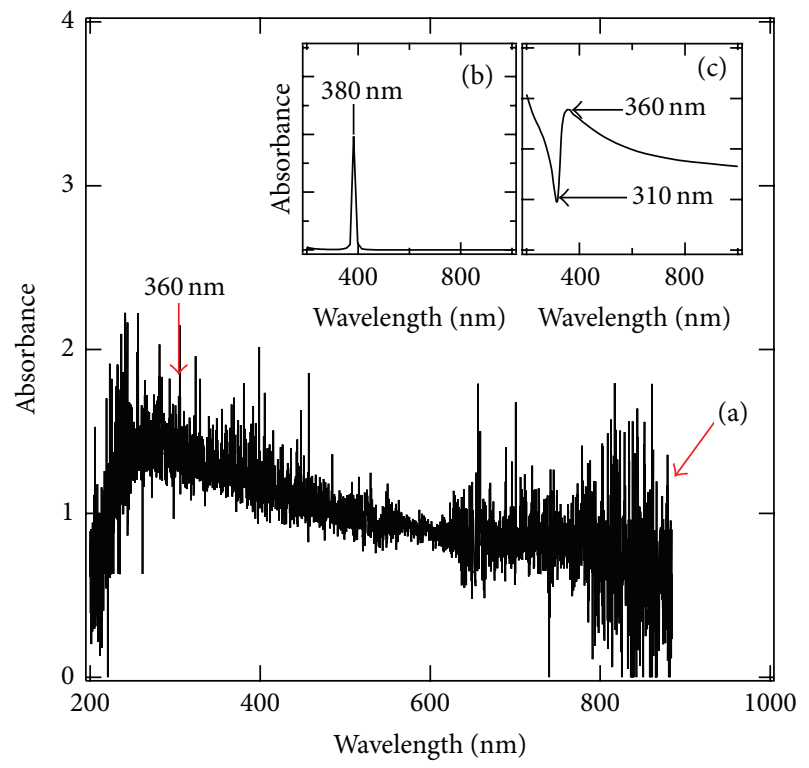

FIGURE 4: A representative absorption-reflection spectrum silver nanofiber deposited on the blood vessels is displayed on (a). The inserts (b) and (c) simulated absorption spectra of silver nanospheres with a diameter of $30 \mathrm{~nm}$ and silver nanowires with a length of $1 \mu \mathrm{m}$ and $50 \mathrm{~nm}$ in diameter, respectively.

from coupling silver through molecular interactions among the thiol molecules. The absorption of light between 200 and $360 \mathrm{~nm}$ in the experimental spectrum likely results from the presence of thiol molecules in the sample.

\subsection{Electron Microscopy Measurements. SEM measurements} were performed to establish the morphology of the nanofibers grown on the surface of the blood vessel walls. A representative image of a region of the interior surface of blood vessels is labeled (a) on the upper left hand side of Figure 5. Representative images of areas of blood vessel surfaces where we have grown the nanofibers are labeled (b), (c), and (d) on Figure 5. The deposit of the nanofibers resembles a mesh of the order of several microns in the SEM image labeled (b). The nanofibers that compose the mesh can be identified in images obtained at slightly higher magnifications, like in Figures 5(c) and 5(d). The diameter and length distribution of the nanofibers grown on the surface of the blood vessels are summarized on Figures 5(e) and $5(f)$, respectively. The nanofibers are $(120 \pm 30) \mathrm{nm}$ in diameter and have lengths of the order of $(2.7 \pm 0.8) \mu \mathrm{m}$.

\subsection{Effect of Silver Nanofibers on the Deformation of the Blood} Vessel Tissue. The squares and circles in Figure 6 represent the displacement of the blood vessel surface as a function of the applied force in a control and nanofiber modified blood vessel, respectively. The deformation of the blood vessel is measured from the displacement of a pin head that exerts the indicated force on a $1.5 \mathrm{~mm}^{2}$ area. There is an initial tension due to the procedure employed to hold the tissues that is taken to be the same on both types of tissue samples; thus, our results must be taken by comparison among the control and modified tissue samples and should not be considered to represent absolute numbers. There is a region where no displacement is detected upon the application of an external force. This region is evident in the data summarized in the insert on the right hand side of Figure 6. The onset of displacement in the control and nanofiber treated blood vessel are observed around $3 \times 10^{-3}$ and $3.4 \times 10^{-1} \mathrm{~N}$, respectively. We conclude that the resistance of the blood vessels toward deformation is increased by the presence of the nanofibers. This is further supported by analysis of the initial slope in the rise of the displacement with applied force. The slope of the initial rise in displacement with applied force is markedly different in both cases. The slopes of the rise in displacement with force are 0.15 and $0.003 \mathrm{~m} / \mathrm{N}$ for the control and nanofibers modified tissue, respectively. The smaller slope in the deformation curve of the blood vessels modified by the nanofibers lead us to conclude that these nanostructures increase the resistance to deform the tissue.

\section{Discussion}

Metallic silver nanofibers form on the internal surface of blood vessel tissues from a silver-thiol dispersion. The silver nanofibers grown on the blood vessel surface are arranged in a mesh-like structure. We estimate a density of silver nanofibers of about 2 nanofibers $/ \mu \mathrm{m}^{2}$ from the SEM measurements. This number is in close agreement to the average length of $(2.7 \pm$ $0.8) \mu \mathrm{m}$ as well as with the peak in the distribution of lengths displayed on Figure 5.

The tunica intima is the layer of blood vessels closest to the blood. It is composed of a thin layer of endothelial cells, an internal elastic lamina and collagen fibers. Bundles of collagen fibrils and collagen fibers are found in the tunica media and tunica adventitia. The collagen fibers have an anisotropic arrangement and are an important element in providing resistance to the pressure load in blood vessels. Collagen is synthesized as pre procollagen, which is a primary structure containing specific regions of glycine, proline, and lysine residues.

Blood vessels modified by the silver nanofibers have a higher resistance toward deformation than control tissues. This is evidenced by the deformation measurements as a function of force. The initial slope of the deformation as a function of applied pressure in blood vessels modified with the silver nanofibers and the control are $0.003 \mathrm{~m} / \mathrm{N}$ and $0.15 \mathrm{~m} / \mathrm{N}$, respectively. Thus, a given force will deform the modified tissue by a smaller amount than the control. This represents an increase in the resistance towards deformation of a factor of 50. This is clinically significant if we consider that blood pressure increases by factors slightly larger than one in the human body.

The blood vessels modified by the silver nanofibers are tissue that can carry the pressure load better than the tissue found in animals and humans. The Young's modulus or elastic modulus is a measure of the stiffness of a material. The elastic modulus $(E)$ is directly proportional to the ratio of the applied 


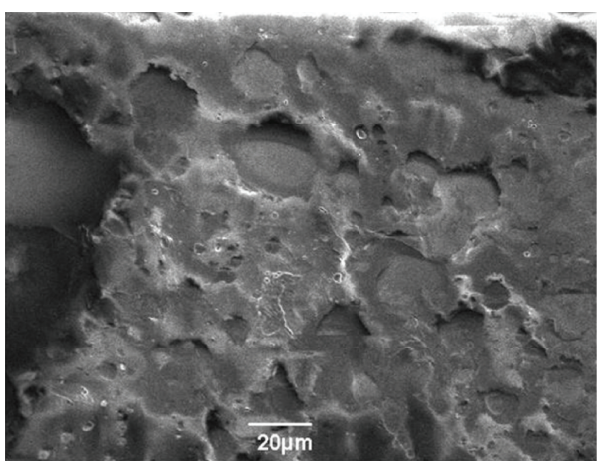

(a)

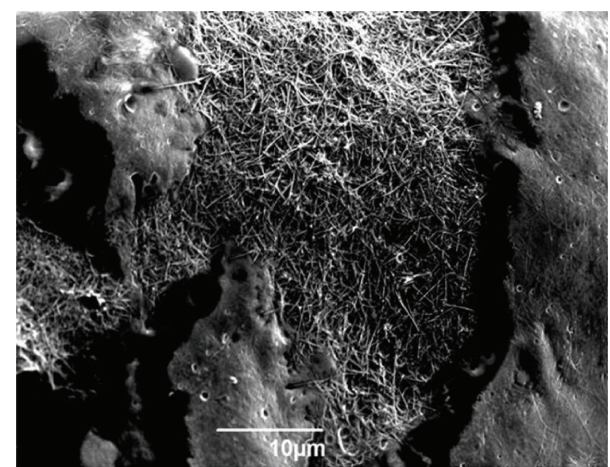

(c)

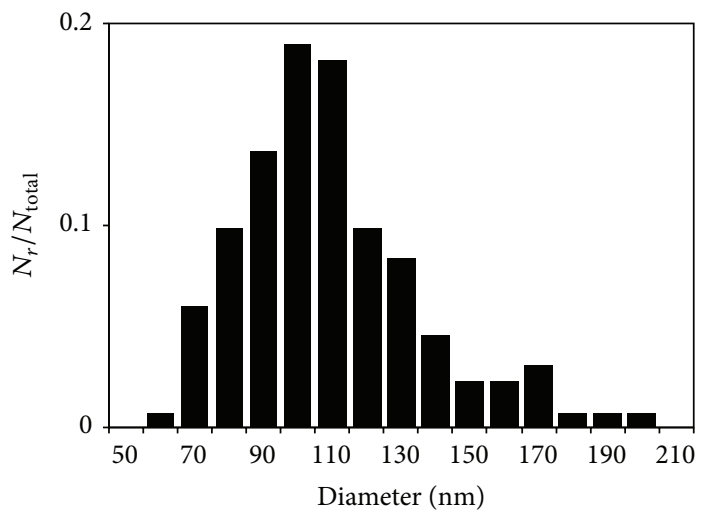

(e)

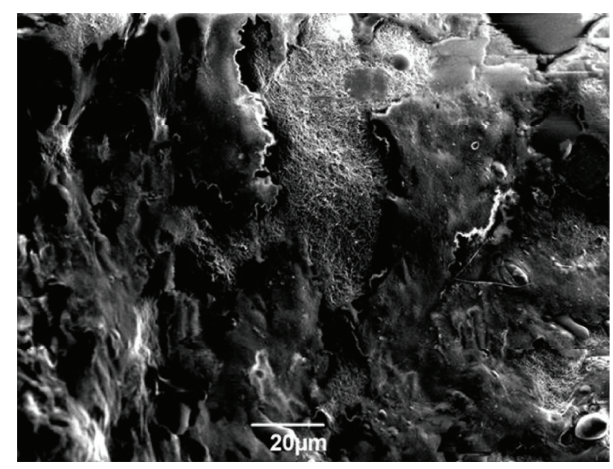

(b)

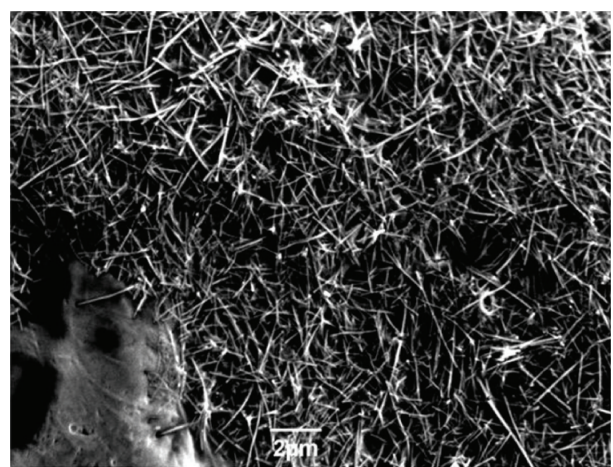

(d)

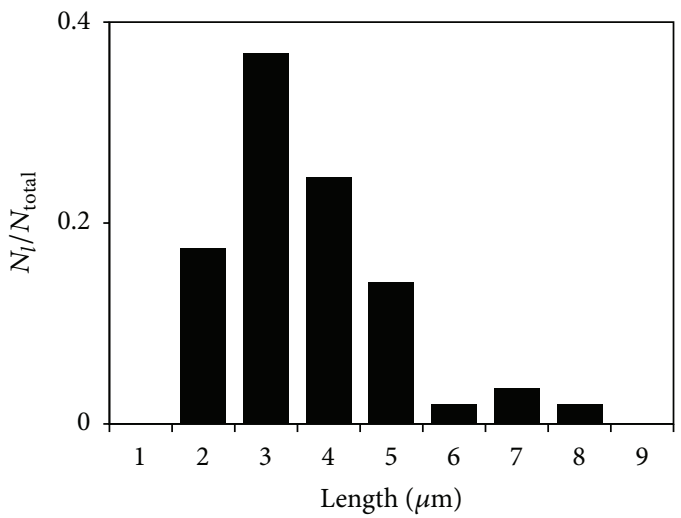

(f)

FIGURE 5: Representative SEM images of (a) the control blood vessel. Images of the surface of a blood vessel where the silver nanofibers were grown are labeled (b), (c), and (d). The diameter and length distribution of the one dimensional nanostructures grown on the surface of the blood vessels are illustrated in (e) and (f), respectively.

force $(F)$ per unit area $(A)$ and inversely proportional to the displacement $(\Delta L)$ relative to the length $\left(L_{o}\right)$ of a material:

$$
E=\frac{(F / A)}{\left(\Delta L / L_{o}\right)} .
$$

An estimate of the elastic modulus of the system composed by the nanofibers on the blood vessel can be obtained from the slope of the dependence of the deformation on applied force. We estimate an elastic modulus between 1 and $3 \times 10^{3} \mathrm{~N} / \mathrm{m}^{2}$ and $0.15 \times 10^{3} \mathrm{~N} / \mathrm{m}^{2}$ for the blood vessels modified with the silver nanofibers and control, respectively. These values fall within the elastic modulus reported for blood vessels $[37,38]$.
The smaller displacement found in the tissue modified silver nanofibers as compared to the original material is consistent with the formation of stiff areas in the modified blood vessels. The risk of rupture of the blood vessel wall is reduced by the resistance towards deformation exhibited by the silver nanofibers treated blood vessel.

The measurements reported here were performed under static conditions and outside the physiological environment where blood vessels are found in humans. Further work in the use of this nanotechnology requires measurements of the effect of pressure on deformation of silver-nanofiber modified blood vessels in a dynamic and pulsed flow set up similar to 


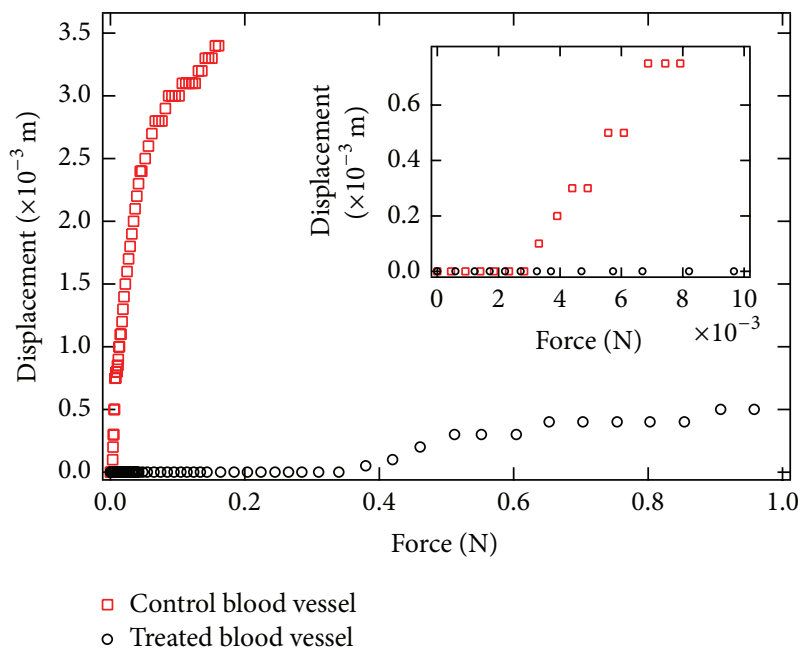

Figure 6: Dependence of the displacement, in meters (m), on the applied force, in newtons $(\mathrm{N})$.

the one found in physiologically relevant environments and with tools to measure the deformation of the blood vessels in vivo [39]. Such experiments are currently outside the reach of our experimental setup and scope, yet this study advances the development of new nanotechnologies based on the use of silver nanostructures to prevent the rupture of aneurysms.

\section{Conflict of Interests}

The authors declare that there is no conflict of interests regarding the publication of this paper.

\section{Acknowledgments}

Miguel Gonzalez and Daniel Rivera acknowledge financial support from the National Institutes of Health RISE2BEST program under Grant no. R25GM088023. Miguel Gonzalez and Daniel Rivera also acknowledge partial financial support from the UPRM Sloan Graduate Program. Alam Marcelino and Gabriela Agront acknowledge support from the NIH/NIDDK Step Up Program Short-Term Education Program, grant number 1R25DK098067-01. Miguel Castro acknowledges support from UPR.

\section{References}

[1] Aneurysm-PubMed Health, 2012, http://www.ncbi.nlm.nih .gov/pubmedhealth/PMH0002109/.

[2] Aneurysm in the brain-PubMed Health, 2012, http://www .ncbi.nlm.nih.gov/pubmedhealth/PMH0002387/.

[3] Abdominal aortic aneurysm-PubMed Health, 2012, http://www .ncbi.nlm.nih.gov/pubmedhealth/PMH0001215/.

[4] D. A. Vorp, "Biomechanics of abdominal aortic aneurysm," Journal of Biomechanics, vol. 40, no. 9, pp. 1887-1902, 2007.

[5] J. C. Lasheras, "The biomechanics of arterial aneurysms," Annual Review of Fluid Mechanics, vol. 39, pp. 293-319, 2007.

[6] Abdominal aortic aneurysm repair-open, 2012, http://www .umm.edu/ency/article/007392all.htm.
[7] Cerebral Aneurysms, 2012, http://emedicine.medscape.com/ article/1161518-overview.

[8] T. Mita, T. Arita, N. Matsunaga et al., "Complications of endovascular repair for thoracic and abdominal aortic aneurysm: an imaging spectrum," Radiographics, vol. 20, no. 5, pp. 1263-1278, 2000.

[9] G. Piffaretti, M. Tozzi, C. Lomazzi, N. Rivolta, R. Caronno, and P. Castelli, "Complications after endovascular stent-grafting of thoracic aortic diseases," Journal of Cardiothoracic Surgery, vol. 1, no. 1, p. 26, 2006.

[10] H. Meng, Z. Wang, Y. Hoi et al., "Complex hemodynamics at the apex of an arterial bifurcation induces vascular remodeling resembling cerebral aneurysm initiation," Stroke, vol. 38, no. 6, pp. 1924-1931, 2007.

[11] R. Taylor and J. J. Norman, Nano and the Future of Endovascular Medicine: A Look at the Medical Advances We Expect in the Coming Decades.

[12] Endovascular image-guided interventions (EIGIs BrowseMedical Physics, 2013, http://online.medphys.org/resource/1/ mphya6/v35/i1/p301_sl?isAuthorized=no.

[13] A. W. Martinez and E. L. Chaikof, "Microfabrication and nanotechnology in stent design," Wiley Interdisciplinary Reviews: Nanomedicine and Nanobiotechnology, vol. 3, no. 3, pp. 256-268, 2011.

[14] E. Fine, L. Zhang, H. Fenniri, and T. J. Webster, "Enhanced endothelial cell functions on rosette nanotube-coated titanium vascular stents," International Journal of Nanomedicine, vol. 4, no. 1, pp. 91-97, 2009.

[15] K. Ishizaki, Y. Sugita, F. Iwasa et al., "Nanometer-thin TiO2 enhances skeletal muscle cell phenotype and behavior," International Journal of Nanomedicine, vol. 6, pp. 2191-2203, 2011.

[16] X. Li, R. Cui, W. Liu et al., "The use of nanoscaled fibers or tubes to improve biocompatibility and bioactivity of biomedical materials," Journal of Nanomaterials, vol. 2013, Article ID 728130, 16 pages, 2013.

[17] H. Plenk Jr., G. M. Cruise, and J. C. Shum, "Hydrogel-coated and platinum coils for intracranial aneurysm embolization compared in three experimental models using computerized angiographic and histologic morphometry," Journal of Materials Chemistry, vol. 17, no. 38, pp. 3965-3973, 2007.

[18] R. H. Baughman, "Playing nature's game with artificial muscles," Science, vol. 308, no. 5718, pp. 63-65, 2005.

[19] J. Choi, Y. Jun, S. Yeon, H. C. Kim, J. Shin, and J. Cheon, "Biocompatible heterostructured nanoparticles for multimodal biological detection," Journal of the American Chemical Society, vol. 128, no. 50, pp. 15982-15983, 2006.

[20] D. K. Yi, S. T. Selvan, S. S. Lee, G. C. Papaefthymiou, D. Kundaliya, and J. Y. Ying, "Silica-coated nanocomposites of magnetic nanoparticles and quantum dots," Journal of the American Chemical Society, vol. 127, no. 14, pp. 4990-4991, 2005.

[21] I.P. Chang, C. H. Kuo, and C. Chiang, "Preparation of fluorescent magnetic nanodiamonds and cellular imaging," Journal of the American Chemical Society, vol. 130, no. 46, pp. 15476-15481, 2008.

[22] Y. Jun, J. Seo, and J. Cheon, "Nanoscaling laws of magnetic nanoparticles and their applicabilities in biomedical sciences," Accounts of Chemical Research, vol. 41, no. 2, pp. 179-189, 2008.

[23] Y.-E. L. Koo, R. Agayan, M. A. Philbert, A. Rehemtulla, B. D. Ross, and R. Kopelman, "Photonic explorers based on multifunctional nanoplatforms: in vitro and in vivo biomedical applications," ACS Symposium Series, vol. 963, pp. 200-218, 2007. 
[24] S. Lal, S. E. Clare, and N. J. Halas, "Nanoshell-enabled photothermal cancer therapy: impending clinical impact," Accounts of Chemical Research, vol. 41, no. 12, pp. 1842-1851, 2008.

[25] M. R. Abidian, K. A. Ludwig, T. C. Marzullo, D. C. Martin, and D. R. Kipke, "Interfacing conducting polymer nanotubes with the central nervous system: chronic neural recording using poly(3,4-ethylenedioxythiophene) nanotubes," Advanced Materials, vol. 21, no. 37, pp. 3722-3770, 2009.

[26] F. Yang, R. Murugan, S. Ramakrishna, X. Wang, Y.-X. Ma, and S. Wang, "Fabrication of nano-structured porous PLLA scaffold intended for nerve tissue engineering," Biomaterials, vol. 25, no. 10, pp. 1891-1900, 2004.

[27] S. L. Bechara, A. Judson, and K. C. Popat, “Template synthesized poly( $\varepsilon$-caprolactone) nanowire surfaces for neural tissue engineering," Biomaterials, vol. 31, no. 13, pp. 3492-3501, 2010.

[28] M. Wahab, P. Schiller, R. Schmidt, and H.-J. Mögel, "Monte Carlo study of the self-assembly of achiral bolaform amphiphiles into helical nanofibers," Langmuir, vol. 26, no. 5, pp. 2979-2982, 2010.

[29] M. Elango, V. Subramanian, A. P. Rahalkar, S. R. Gadre, and N. Sathyamurthy, "Structure, energetics, and reactivity of boric acid nanotubes: a molecular tailoring approach," Journal of Physical Chemistry A, vol. 112, no. 33, pp. 7699-7704, 2008.

[30] E. A. Hernandez, B. Posada, R. Irizarry, and M. E. Castro, "Role of hydrogen bonding interactions in directing one-dimensional thiol-assisted growth of silver-based nanofibers," Journal of Physical Chemistry B, vol. 109, no. 15, pp. 7251-7257, 2005.

[31] N. A. Kotov, Ed., Nanoparticle Assemblies and Superstructures, CRC Press, New York, NY, USA, 2005.

[32] CDC-DHDSP-Fact Sheets-Aortic Aneurysm Fact Sheet, 2012, http://www.cdc.gov/dhdsp/data_statistics/fact_sheets/fs_ aortic_aneurysm.htm.

[33] W. D. Clouse, J. W. Hallett Jr., H. V. Schaff et al., "Acute aortic dissection: population-based incidence compared with degenerative aortic aneurysm rupture," Mayo Clinic Proceedings, vol. 79, no. 2, pp. 176-180, 2004.

[34] D. Lloyd-Jones, R. J. Adams, T. M. Brown et al., "Executive summary: heart disease and stroke statistics-2010 update: a report from the american heart association," Circulation, vol. 121, no. 7, pp. e46-e215, 2010.

[35] J. J. A. Mooij, "Neurosurgery [Springer: Erste Auflage]," in European Manual of Medicine, C. B. Lumenta, C. Di Rocco, and J. Haase, Eds., vol. 3, Springer, New York, NY, USA, 2010.

[36] E. Mercado, S. Santiago, L. Baez et al., "One-dimensional silver nanostructures on single-wall carbon nanotubes," Nanoscale Research Letters, vol. 6, p. 602, 2011.

[37] R. L. Wesly, R. N. Vaishnav, and J. C. A. Fuchs et al., "Static linear and nonlinear elastic properties of normal and arterialized venous tissue in dog and man," Circulation Research, vol. 37, no. 4, pp. 509-520, 1975.

[38] J. Fromageau, S. Lerouge, R. L. Maurice, G. Soulez, and G. Cloutier, "Noninvasive vascular ultrasound elastography applied to the characterization of experimental aneurysms and follow-up after endovascular repair," Physics in Medicine and Biology, vol. 53, no. 22, pp. 6475-6490, 2008.

[39] C. Robertson, K. Ikemura, T. B. Krasieva, and S. C. George, "Multiscale analysis of collagen microstructure with generalized image correlation spectroscopy and the detection of tissue prestress," Biomaterials, vol. 34, no. 26, pp. 6127-6132, 2013. 

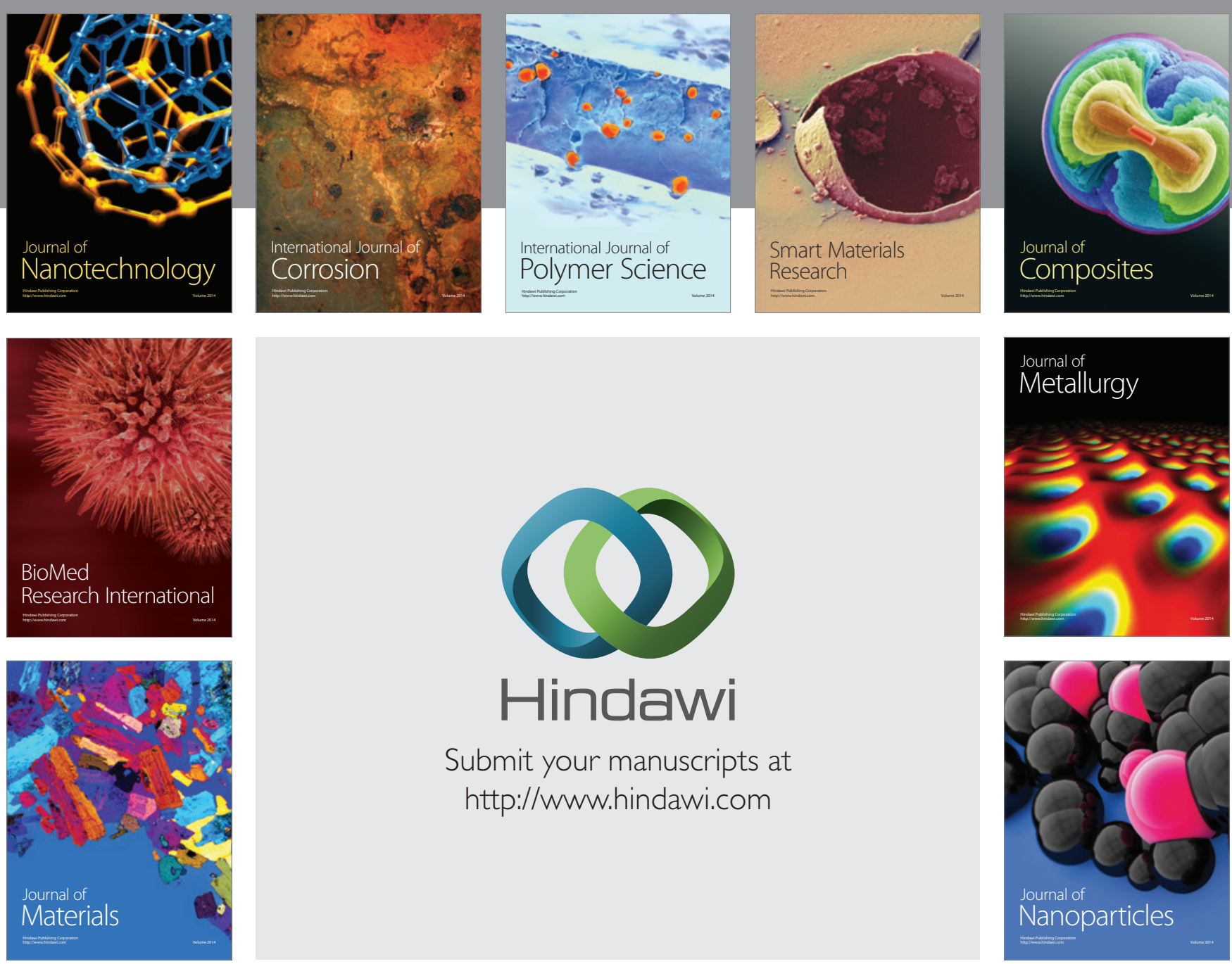

Submit your manuscripts at http://www.hindawi.com
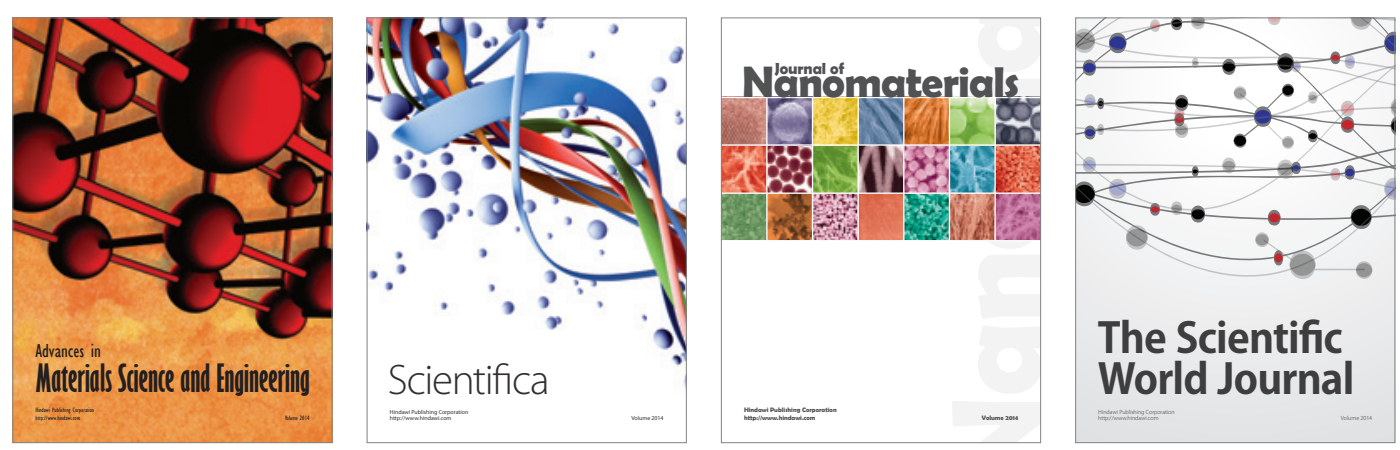

\section{The Scientific World Journal}
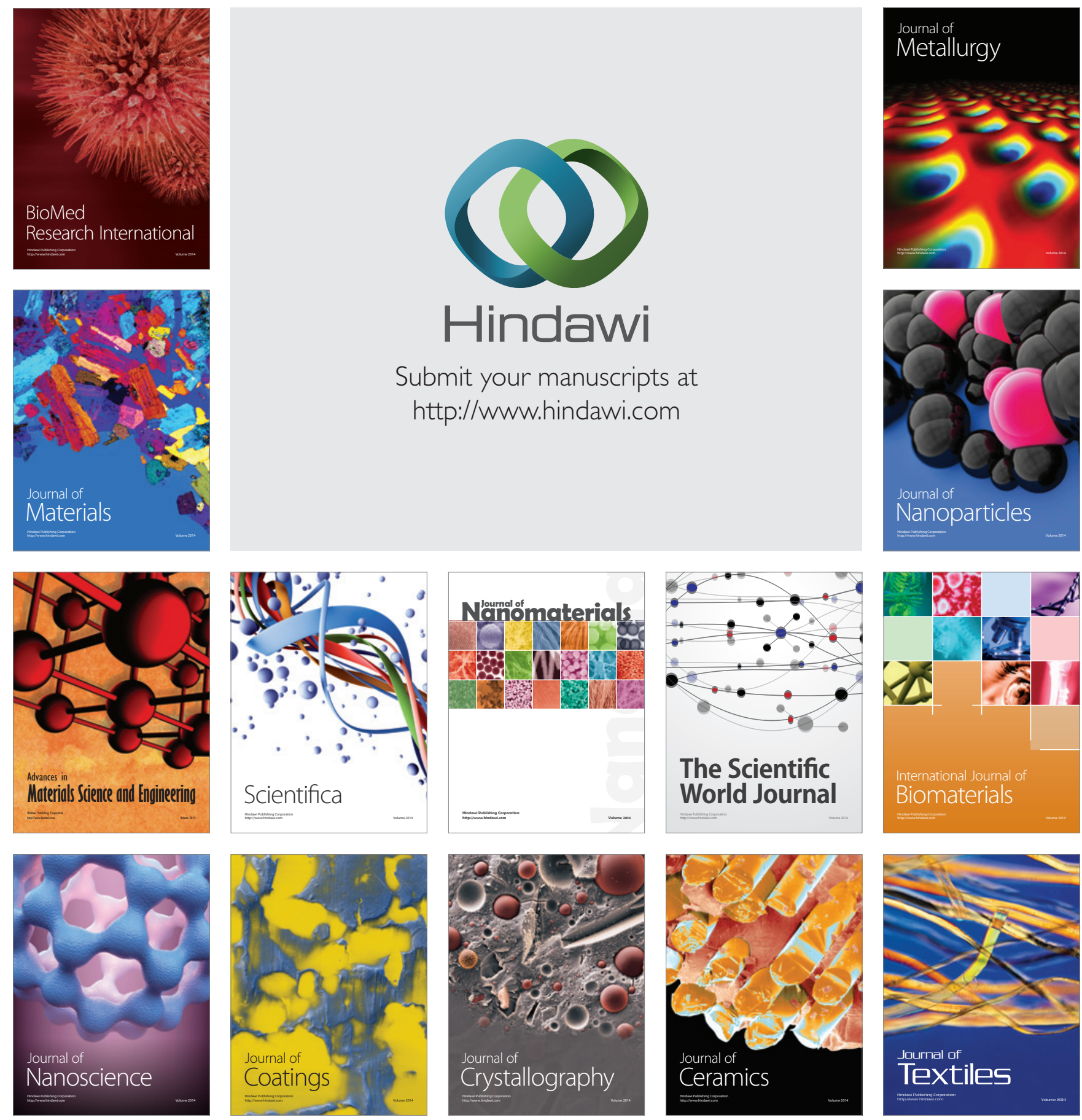